\title{
Biomarkers in systemic sclerosis
}

Systemic sclerosis is an autoimmune inflammatory disorder of unknown etiology characterized by pronounced fibroproliferative alterations in the microvasculature, and frequent cellular and humoral immunity abnormalities, culminating in a severe and often progressive fibrotic process. Numerous biomarkers reflecting the three main pathogenetic mechanisms in systemic sclerosis have been described; however, aside from several disease-specific autoantibodies, other biomarkers have not been thoroughly validated and require further study. Thus, there is an unmet need for validated biomarkers for diagnosis, disease classification, and evaluation of organ involvement and therapeutic response in systemic sclerosis.

\section{KEYWORDS: biomarker endothelial cells fibrosis pulmonary artery hypertension pulmonary fibrosis scleroderma systemic sclerosis TGF- $\beta$}

Systemic sclerosis (SSc) is an idiopathic systemic autoimmune disease, characterized by three pathological processes:

- Severe and often progressive cutaneous and visceral fibrosis;

- Fibroproliferative vasculopathy;

- Pronounced cellular and humoral immunity abnormalities [1-4].

Clinically, SSc is heterogeneous, ranging from indolent and limited skin sclerosis confined to the fingers, face and/or distal parts of the extremities (sclerodactyly or acrosclerosis) to diffuse and progressive skin involvement. The visceral involvement also ranges from limited and usually nonprogressive alterations to severe fibrosis of multiple internal organs and, occasionally, a fulminant course with a rapid development of vital organ failure and a lethal outcome (fulminant SSc) [5]. The most apparent and almost universal clinical features of SSc are related to the progressive fibrosis of the skin, the microvasculature and numerous internal organs. Morbidity and mortality in SSc are high, and are related to the extent of the fibrotic and microvascular alterations. The extent and rate of progression of tissue fibrosis is of paramount importance in determining the clinical features and the prognosis of SSc. Indeed, fibrosis of the skin correlates with both survival and functional limitations [5-7].

The etiology of SSc is not known, however, it is currently accepted that the disease results from complex interactions between one or more environmental factors and a genetic predisposition in the host [1-4]. These genetic-environmental interactions eventually result in the development of skin and tissue fibrosis accompanied by a severe fibroproliferative/occlusive vasculopathy and abnormalities in cellular and humoral immunity with the occurrence of chronic inflammatory cell infiltration, derangement of cytokine and growth factor functional balance, and development of numerous autoantibodies, as illustrated in Figure $1[3,4,8]$. At present, it is not clear which of these components of SSc pathogenesis is of primary importance or how they interrelate to cause the progressive fibrotic process. However, numerous studies have recently suggested that there is a sequence of pathogenetic events initiated by unknown etiologic factors, which trigger microvascular injury with prominent structural and functional endothelial cell abnormalities that result in progressive fibroproliferative vasculopathy and vessel rarefaction [9-11]. The endothelial activation also leads to the attraction of specific cellular elements from the bloodstream and bone marrow, and their transmigration into the surrounding tissue. This cellular migration and accumulation leads to the establishment of a chronic inflammatory process with participation from macrophages and $\mathrm{T}$ and $\mathrm{B}$ lymphocytes, and the secretion and release of a variety of cytokines and growth factors from these cells. This sequence of events, diagrammatically illustrated in Figure 2, culminates in the development of a severe and progressive fibrotic process and in the production of disease-specific autoantibodies.

Remarkable recent progress in understanding numerous basic mechanisms involved in the complex pathogenesis of SSc has opened new
Susan V Castro

\& Sergio A Jimenez ${ }^{\dagger}$ ${ }^{+}$Author for correspondence: Jefferson Institute of Molecular Medicine, Thomas Jefferson University, 233 S. 10th Street Room 509 BLSB, Philadelphia, PA 19107-15541, USA Tel.: +1 2155035042 Fax: +12159234649 sergio.jimenez@jefferson.edu 


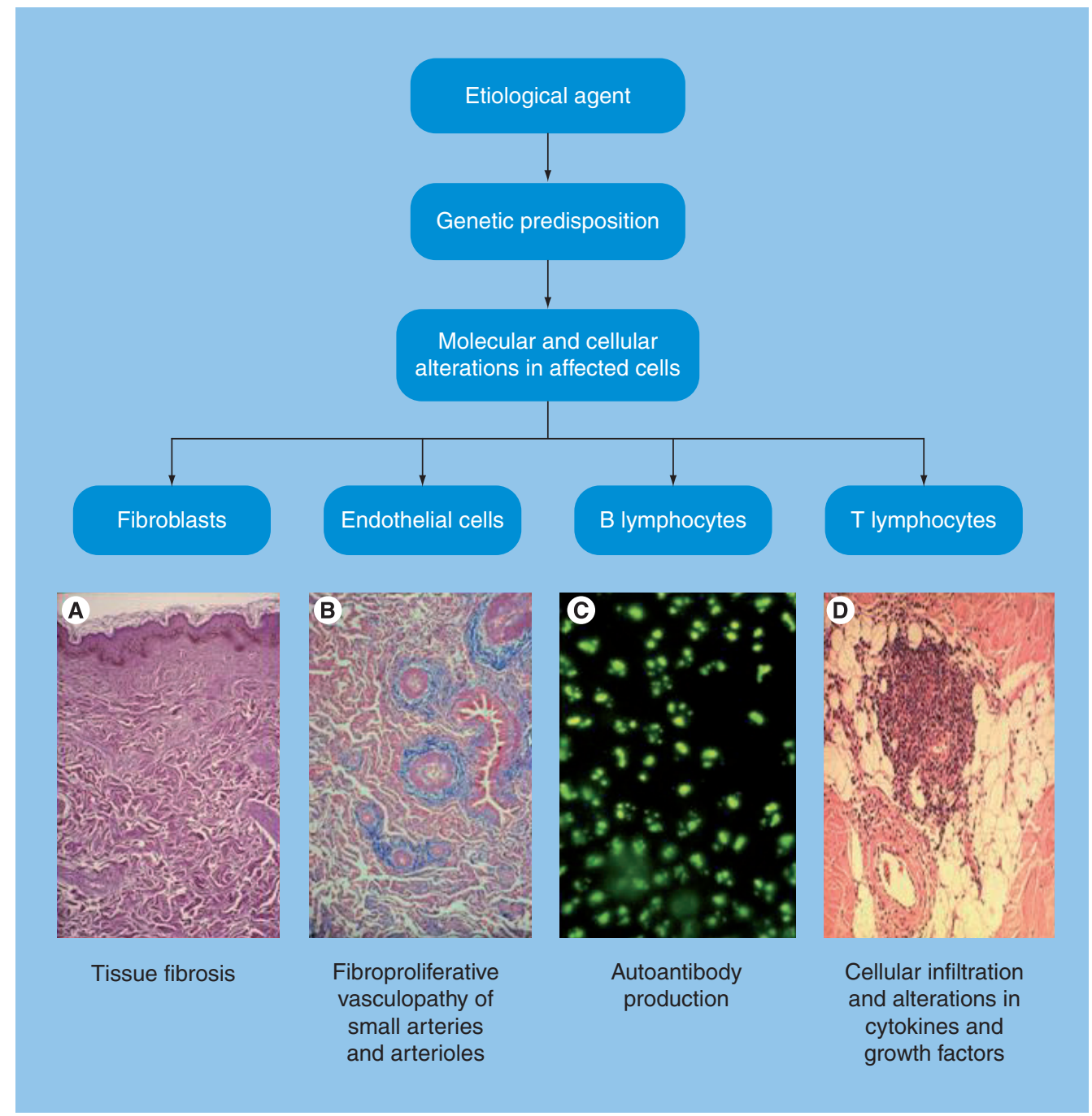

Figure 1. General overview of the pathogenesis of systemic sclerosis. Illustrations on the bottom row show examples of (A) the fibrotic process (biopsy of skin), (B) microvascular alterations in pulmonary arterioles, (C) autoantibodies detected by immunofluorescence and (D) mononuclear inflammatory cell infiltrates in affected skin.

Adapted with permission from [3].

avenues for the development of novel and effective therapeutic approaches. At the same time, it has become apparent that there is an unmet need for validated biomarkers that can be used for diagnosis, disease classification, identification of organ involvement and evaluation of therapeutic response in SSc.

\section{Biomarkers in SSC}

The NIH Biomarkers Definitions Working Group was convened by the NIH Director's initiative on Biomarkers and Surrogate End points. The expert working group provided definitions, and identified the characteristics and requirements of biological measurements to be employed for the development and assessment of human therapeutics. A 'biological marker' or 'biomarker' was defined as a characteristic that is objectively measured and evaluated as an indicator of normal biologic processes, pathogenic processes or pharmacologic responses to a therapeutic intervention. Other important characteristics of a biomarker include the following: it should reflect the underlying biologic process being evaluated; should allow the prediction of the clinical course or prognosis of a disease process; should be sensitive to therapeutic effects; should be easily obtainable, preferably by noninvasive means; and should eventually be validated in clinical studies.

Although there has been extensive interest in the development of outcome measures for SSc [12-16], biomarkers that allow early diagnosis and assessment of disease activity or that carry a predictive prognostic value are not available for SSc. The clinical semi-quantitative assessment 
of skin thickness (modified Rodnan skin score [mRSS]) is currently the gold standard and the only outcome measure used in clinical trials of SSc disease-modifying agents. The original description of the method demonstrated that the score correlated with skin biopsy sample weight and, thus, it was assumed to be a reflection of the fibrotic process causing skin induration and thickening. Although noninvasive and cost effective, the mRSS entails several shortcomings, ranging from the subjectivity of skin palpation assessments to the difficulty of scoring borderline changes in skin involvement. Furthermore, it is not possible to differentiate fibrotic skin

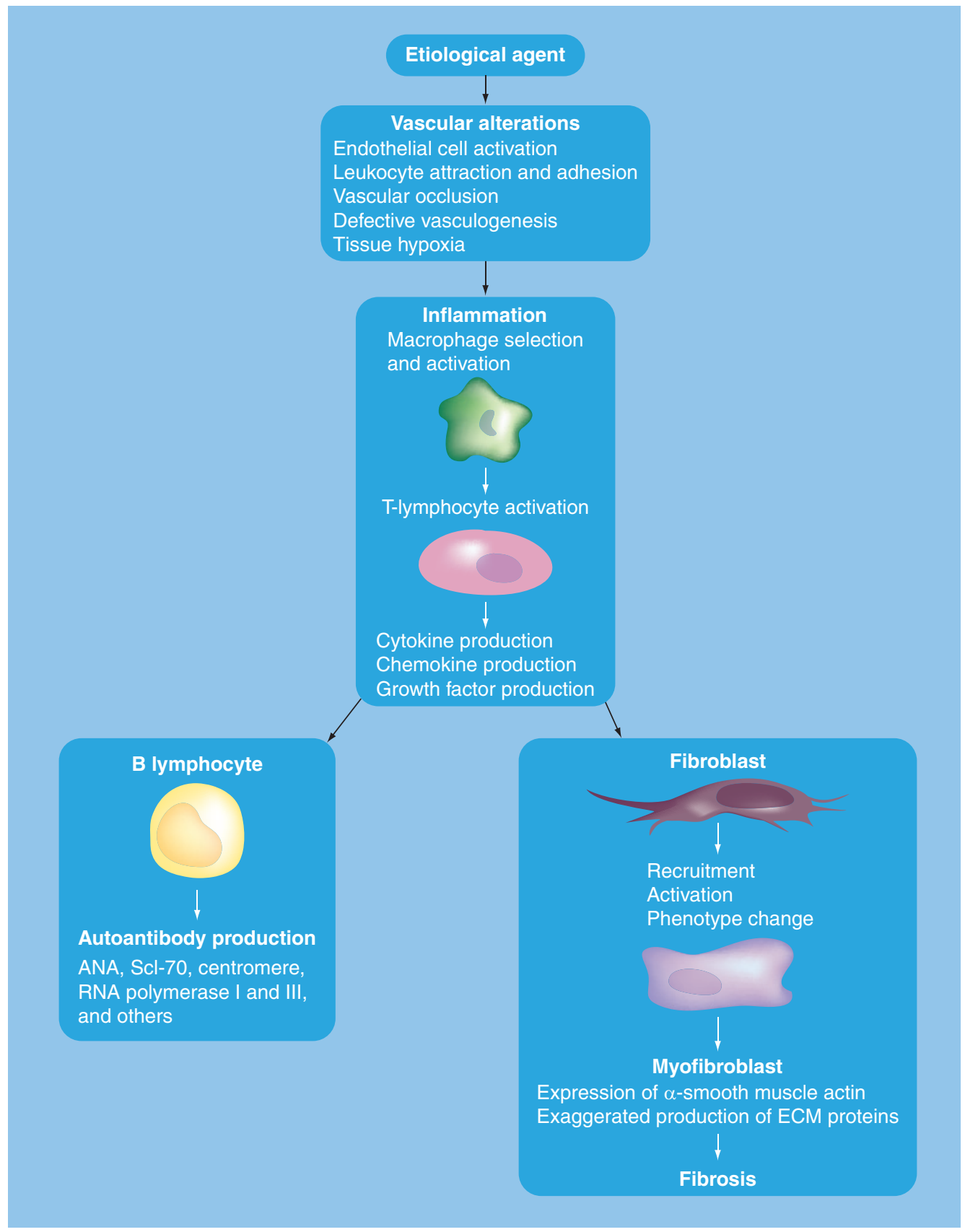

Figure 2. Postulated sequence of events in the pathogenesis of systemic sclerosis.

Sequence of pathogenic processes leading to tissue fibrosis and autoantibody production.

The process is initiated by microvascular endothelial injury, which induces chronic inflammation with participation of macrophages and T lymphocytes, as well as B-lymphocyte activation, leading to autoantibody production. The secreted products from the inflammatory cells result in fibroblast activation and phenotypic conversion into myofibroblasts; key events in the development of fibrosis. ANA: Antinuclear antibody; ECM: Extracellular matrix; Scl-70: Scleroderma-70 antibody (anti-DNA topoisomerase 1). 
thickening from that resulting from tissue edema, inflammation, vascular-bed engorgement or skin tethering. It is, therefore, generally accepted that the development of objective and reliable markers to reflect the severity of tissue fibrosis would be of invaluable help in determining the efficacy of a given treatment in clinical trials, both by allowing a reduction in the number of patients needed for the studies to achieve statistical power and by offering an objective and quantitative method independent of the subjective assessment of the investigators involved in the study.

By contrast to the remarkable progress of biomarkers in cancer and cardiovascular disease [17-20], there are very few validated biomarkers for the assessment of SSc disease activity and for clinical subset disease classification, and their utility has not been extensively tested or validated in clinical trials [21]. Most importantly, there is an important need to develop, test and validate accurate and objective measures of tissue fibrosis and vasculopathy in SSc and markers that may reflect a therapeutic response of the disease process for use in clinical trials.

Biomarkers for SSc can be grouped based on their ability to assist in SSc diagnosis ('diagnostic biomarkers'), to determine distinct clinical subsets that may have specific patterns of organ involvement or evolution ("clinical subset biomarkers'), or to predict specific organ involvement or specific clinical manifestations, such as tissue fibrosis ('fibrosis biomarker') or vascular alterations ('vascular biomarker'). Other biomarkers should allow assessment of disease activity, including prediction of the clinical course or mortality ('prognostic biomarker'), or determination of the effectiveness of a therapeutic intervention ('therapeutic response biomarker'). This latter group of biomarkers are also often utilized as end points in the clinical trials of potential treatments or interventions.

\section{Autoantibodies as SSc diagnostic biomarkers}

At present there are no specific diagnostic tests for SSc and the disorder is diagnosed primarily based on the collective appearance of a cluster of clinical symptoms, such as Raynaud's phenomenon, telangiectasias, esophageal dysfunction with gastro-esophageal reflux, characteristic pigmentary changes, or presence of digital ulcers or calcinotic lesions accompanying clinically detectable skin induration. Indeed, the diagnostic criteria commonly employed for the classification of SSc are entirely based on clinical manifestations and do not include any measurable serologic or laboratory parameters. However, it is well recognized that the presence of specific autoantibodies is one of the most common manifestations of SSc and greater than $90 \%$ of SSc patients harbor antinuclear antibodies in their serum [22-25]. Numerous autoantibodies have been described in SSc patients (Table 1). Some of these are highly specific for SSc, including anti-Scl-70 and anticentromere antibodies, and these have, therefore, been used as diagnostic biomarkers to support or confirm the clinical diagnosis of SSc. Anti-Scl-70 antibodies are directed against DNA topoisomerase I and are almost exclusively present in the sera of patients with the diffuse form of SSc [26,27]. Anti-Scl-70 antibodies also correlate with the development of severe interstitial lung disease. Anticentromere antibodies recognize several protein components of the tri-laminar kinetochore [28]. These antibodies are usually present in patients with the limited form of SSc and are found in $45-50 \%$ of these patients. In contrast to anti-Scl-70 antibodies, anticentromere antibodies are only found in approximately $10 \%$ of patients with diffuse SSc. These two autoantibodies are mutually exclusive, coexisting in the same patient only in rare instances.

There are numerous other autoantibodies less commonly present in SSc patients, including anti-RNA polymerase I and III antibodies in patients with rapidly progressive diffuse disease and a high frequency of SSc renal crisis, antifibrillarin antibodies commonly found in diffuse SSc, and anti-PM-Scl antibodies that are often present in patients with a polymyositis/SSc overlap syndrome [29-31].

\section{Biomarkers for clinical disease subset classification}

It has long been recognized that there are at least two distinct clinical subsets of SSc differing in their clinical presentation and evolution, but most importantly, with clearly different outcomes regarding frequency and severity of organ involvement as well as overall mortality [5,32-34]. The extent of cutaneous sclerotic involvement has been found to accurately distinguish the two clinical subsets in the majority of cases. The first subset is characterized by diffuse cutaneous involvement, frequently including the thighs, abdomen and chest, and is associated with a progressive course and frequent and severe visceral organ involvement occurring in the early stages of disease evolution including the development of SSc renal crisis and pulmonary fibrosis, 
and high SSc-related mortality. By contrast, in the second subset there is limited cutaneous involvement confined to the acral parts of the extremities and the face, usually displaying a more prolonged and protracted evolution, lesser severity of visceral organ involvement except for the relatively common occurrence of pulmonary arterial hypertension $(\mathrm{PAH})$ at a late stage of

\section{Table 1. Potential biomarkers for systemic sclerosis diagnosis, clinical subset classification and process/organ involvement.}

\begin{tabular}{|c|c|c|c|}
\hline Biomarker & Class/function & Clinical association & $\begin{array}{l}\text { Response to } \\
\text { treatment }\end{array}$ \\
\hline \multicolumn{4}{|c|}{ Diagnostic \& clinical subset classification } \\
\hline Anti-Scl-70 & Anti-DNA topoisomerase I antibody & $\begin{array}{l}\text { Diffuse SSC, } \\
\text { pulmonary fibrosis }\end{array}$ & No \\
\hline Anticentromere & Anti-kinetochore protein antibody & $\begin{array}{l}\text { Limited SSC, } \\
\text { pulmonary hypertension }\end{array}$ & No \\
\hline $\begin{array}{l}\text { Anti-RNA polymerase I, anti-RNA } \\
\text { polymerase III }\end{array}$ & Antibodies to RNA polymerases & Diffuse SSC, renal involvement & No \\
\hline Antifibrillarin & $\begin{array}{l}\text { Antibody to } 34 \mathrm{kDa} \text { nucleolar protein } \\
\text { component of U3-RNP }\end{array}$ & Diffuse SSC & No \\
\hline Anti-PM-SCl & $\begin{array}{l}\text { Antibody to complex of } 110-120 \text { kDA } \\
\text { nucleolar and nuclear proteins }\end{array}$ & Polymyositis/SSc overlap & No \\
\hline Anti-Th/To & $\begin{array}{l}\text { Antibody to RNAse P } \\
\text { ribonucleoprotein complexes }\end{array}$ & Limited SSc & No \\
\hline \multicolumn{4}{|l|}{ Vascular } \\
\hline von Willebrand factor & Hemostasis & $\begin{array}{l}\text { Endothelial cell dysfunction, } \\
\text { SSc severity, interstitial lung } \\
\text { disease extent }\end{array}$ & Unknown \\
\hline Adhesion molecules & Cell-cell interactions & Endothelial cell dysfunction & Unknown \\
\hline VEGF & Growth factor & Endothelial cell dysfunction & Unknown \\
\hline \multicolumn{4}{|l|}{ Fibrotic } \\
\hline Type III procollagen peptides & $\begin{array}{l}\text { Fibroblast and endothelial cell extracellular } \\
\text { matrix protein }\end{array}$ & $\begin{array}{l}\text { Pulmonary involvement, } \\
\text { poor prognosis/survival }\end{array}$ & Yes \\
\hline TGF- $\beta$ & Growth factor & Fibrosis & Unknown \\
\hline CTGF & Growth factor & Fibrosis & Unknown \\
\hline Cartilage oligomeric matrix protein & $\begin{array}{l}\text { Cartilage and fibroblast extracellular } \\
\text { matrix protein }\end{array}$ & Fibrosis & Unknown \\
\hline \multicolumn{4}{|l|}{ Immunologic (cytokines \& chemokines) } \\
\hline Soluble receptor for IL-2 & $\begin{array}{l}\text { Inflammatory and immune } \\
\text { system alterations }\end{array}$ & Chronic inflammatory process & Unknown \\
\hline Soluble receptor for TNF- $\alpha$ & $\begin{array}{l}\text { Inflammatory and immune } \\
\text { system alterations }\end{array}$ & Chronic inflammatory process & Unknown \\
\hline \multicolumn{4}{|l|}{ Pulmonary hypertension } \\
\hline Endothelin-1 & Vasoconstrictor, endothelial cell product & $\begin{array}{l}\text { Pulmonary artery } \\
\text { hypertension }\end{array}$ & Yes \\
\hline $\mathrm{N}$-terminal probrain natriuretic peptide & $\begin{array}{l}\text { Myocardial protein induced by } \\
\text { mechanical stretch }\end{array}$ & $\begin{array}{l}\text { Pulmonary artery } \\
\text { hypertension }\end{array}$ & Yes \\
\hline \multicolumn{4}{|l|}{ Pulmonary fibrosis } \\
\hline Krebs von den Lungen 6 antigen & $\begin{array}{l}\text { Mucinous glycoprotein from } \\
\text { type II pneumocytes }\end{array}$ & Pulmonary fibrosis & Yes \\
\hline Pulmonary surfactant $A$ & Product of type II pneumocytes & Pulmonary fibrosis (sensitive) & Yes \\
\hline Pulmonary surfactant D & Product of type II pneumocytes & Pulmonary fibrosis (specific) & Unknown \\
\hline $\begin{array}{l}\text { Pulmonary and activation } \\
\text { regulated chemokine }\end{array}$ & Chemokine & Pulmonary fibrosis & Unknown \\
\hline $\begin{array}{l}\text { YKL-40 (human cartilage } \\
\text { glycoprotein-39) }\end{array}$ & Tissue remodeling & Pulmonary fibrosis & Unknown \\
\hline
\end{tabular}


the disease, and a more benign prognosis with prolonged overall survival. When fully established, the two clinical SSc subsets display clearly distinguishable patterns of cutaneous involvement, however, in early stages of presentation their manifestations often overlap. Thus, there is a substantial requirement for biomarkers that accurately identify clinical SSc subsets at early stages of disease. Although currently there are no specific biomarkers to separate these two clinical subsets, the pattern of antinuclear autoantibodies present in the sera of affected individuals can be considered as biomarkers of the pattern of disease subset; anticentromere antibodies are almost exclusively present in the limited SSc subset, whereas Scl-70, anti-RNA polymerase I and III, and antifibrillarin antibodies are almost exclusively associated with the diffuse form of SSc [22-31].

\section{Biomarkers of endothelial cell dysfunction}

Vascular dysfunction is considered to be one of the earliest clinical manifestations of SSc and it has been suggested to be a crucial initiating event in SSc pathogenesis (Figure 2) [9-11,35-38]. Endothelial injury leads to vascular fibroproliferative lesions in multiple organs; however, the effects of vascular dysfunction are most dramatic when they involve the pulmonary and renal arterioles, causing renal crisis and $\mathrm{PAH}$, respectively - the two most prevalent causes of morbidity and mortality in patients with SSc.

Since the pioneering studies by Kahaleh and LeRoy, focusing attention on the important role of endothelial cells in SSc pathogenesis and originally demonstrating that specific endothelial cell proteins such as the von Willebrand factor (vWf) are abnormally elevated in the sera of patients with SSc [36], there has been intense investigation and numerous studies have described potentially important biomarkers that may provide information about the functional status of endothelial cells and their dysfunction in SSc [39-43]. In the original study of Kahaleh, vWf was found elevated in the plasma of patients with SSc and patients with Raynaud's phenomenon in comparison with normal controls [36]. These studies have subsequently been confirmed, and it has been suggested that this biomarker correlates with the severity of SSc [39], the presence of pulmonary involvement [44] and the extent of radiologically demonstrated interstitial lung disease [45]. Of interest was the observation that ADAMTS-13, an enzyme involved in the cleavage and processing of vWf, was found to be reduced in patients with SSc, suggesting that measurements of the activity of this enzyme may represent a biomarker of vascular involvement or endothelial cell dysfunction in patients with the disorder [46].

Numerous other molecules involved in different aspects of the pathogenesis of endothelial dysfunction in SSc have also been suggested as potential biomarkers for endothelial perturbations in the disorder. Among these are circulating levels of adhesion molecules, thrombospondin, thrombomodulin, endothelin (ET)-1, the $\mathrm{N}$-terminal pro-peptide of the brain natriuretic peptide (NT-pro-BNP), VEGF, endostatin, plasminogen activator and metabolites of the arachidonic acid cascade, such as prostacyclin and thromboxane or nitrous oxide circulating metabolites.

Endothelin-1 is a 21-amino acid polypeptide produced by endothelial cells that is capable of potent vasoconstriction and is able to stimulate proliferation of smooth muscle cells. Numerous studies have conclusively demonstrated that ET-1 and its specific cellular receptors play a crucial role in the proliferative vasculopathy of $\mathrm{SSc}$, in particular, in the vascular alterations of SSc-associated PAH [47-50]. Thus, there has been intense interest in ET-1 measurement as a biomarker of SSc vasculopathy. Serum ET-1 levels have been found to be elevated in the plasma of SSc patients and to increase following cold exposure and triggering of Raynaud's phenomenon. Elevated ET-1 levels correlated with other indicators of endothelial cell activation, such as increased vWf, as well as with the levels of other endothelial cell proteins, such as thrombomodulin and adhesion molecules, including soluble ICAM-1 and soluble VCAM-1 Furthermore, immunohistochemistry studies demonstrated the presence of an elevated expression of ET-1 and ET receptors in pulmonary parenchyma at early stages of development of interstitial lung disease and fibrosing alveolitis of SSc [51]. These observations suggested that ET-1 measurements may not only reflect crucial alterations in endothelial cell function involved in the pathogenesis of $\mathrm{PAH}$, but may also be indicators of the profibrotic activity responsible for the exaggerated production of connective tissue macromolecules characteristic of the disease.

Adhesion molecules involved in cell-cell and cell-extracellular matrix interactions are also important in the pathogenesis of the earlier stages of vascular alterations in SSc and have been suggested as potential biomarkers for SSc 
vasculopathy. Increased expression of ELAM-1, ICAM-1, VCAM-1, e-selectin and p-selectin have been found in affected skin from SSc patients, with higher levels present in samples from the diffuse form of the disease, indicating that these proteins may participate in the early stages of tissue fibrosis as well. Elevated serum levels of these adhesion molecules have been found in SSc patients compared with normal individuals [52-54] and other studies demonstrated that these levels correlated with increased severity and extent of visceral organ involvement in the disease [55].

Numerous recent studies have also demonstrated that in addition to functional abnormalities in endothelial cells in SSc there might be abnormalities in angiogenesis and endothelial repair. The rarefaction of small capillaries with a reduction in capillary density in affected SSc tissues is consistent with abnormal and disordered angiogenesis. Therefore, markers that may reflect the angiogenesis process have been suggested to be important in the evaluation of vascular alterations in SSc [56]. One of the key mediators of angiogenesis, VEGF, has been studied extensively as a potential biomarker for the vascular abnormalities in SSc [41,42,56-58]. Indeed, high VEGF levels have been found in patients with early SSc, and these levels correlated with the presence of pulmonary fibrosis and abnormalities in pulmonary function, including reductions in vital capacity and the diffusing capacity of the lung for carbon monoxide. High levels of VEGF were also found to correlate with a shorter disease duration as well as with aggressive and rapidly progressive diffuse cutaneous SSc, although other studies failed to show such a correlation [59].

\section{Biomarkers of PAH}

Pulmonary artery hypertension has recently emerged as one of the most important and serious clinical problems in patients with SSc $[60,61]$. Although PAH is not the most common pulmonary involvement in SSc patients, it frequently leads to severe respiratory disability and often to a fatal outcome with a high mortality. In most instances the clinical course of untreated PAH is one of rapid progression leading to respiratory failure or death within 2-3 years after it becomes clinically detectable. Currently, owing to the remarkable reduction in mortality from SSc renal crisis, it is apparent that $\mathrm{PAH}$ has become one of the leading causes of mortality in this disease $[60,62]$. PAH in patients with SSc can occur as sequelae to interstitial lung disease, although it often develops as a late manifestation in patients with the limited cutaneous form of SSc in the absence of pulmonary fibrosis. There are currently no validated laboratory tests or serologic markers that can provide a specific diagnostic for PAH. However, given the important role that ET-1 plays in the pathogenesis of $\mathrm{PAH}$ and the remarkable clinical effects and survival improvement resulting from the therapeutic use of ET-1-receptor blockade, measurements of circulating ET-1 levels were examined as possible biomarkers for SSc-related PAH [50,51]. A more recent study demonstrated that ET-1 plasma levels were significantly higher in SSc patients with PAH and with positive anticentromere antibodies. Furthermore, there was a positive linear correlation between these levels and systolic pulmonary artery pressure [63]. Thus, it was suggested that ET-1 plasma levels may be a biomarker for the detection and monitoring of PAH in SSc. Recent interest has also been focused on the measurement of plasma levels of NT-pro-BNP. Although the plasma levels of this peptide reflect myocardial responses to various stimuli, such as mechanical stretch or hypoxia and are not specific for PAH, plasma NT-pro-BNP determinations may predict prospectively the development of clinical PAH, and may also be indicative of survival and represent an accurate surrogate marker to follow the response and evaluate the effects of therapeutic agents for SSc-related PAH [64-68].

\section{Biomarkers of pulmonary fibrosis}

In recent years, interstitial lung disease associated with SSc has become the leading cause of morbidity and mortality in SSc [69]. Thus, the search for biomarkers that may predict the development of pulmonary fibrosis, and/or correlate with the clinical course and clinical response to potential therapeutic agents, has become an important goal and numerous studies have been performed to identify such biomarkers [70,71]. Substantial interest has been placed on proteins that are synthesized, produced and secreted by type II alveolar epithelial cells. Some of these proteins appear to predict the progression of interstitial lung involvement and may also represent early markers indicative of the development of this complication. Three proteins that appear to be specific for pulmonary involvement are the Krebs von den Lungen 6 antigen (KL-6) and pulmonary surfactants A and D (PS-A and -D). Several studies have demonstrated that serum levels of KL-6, as measured by ELISA, are substantially higher in SSc patients than in normal 
individuals [72-74]. Furthermore, these levels were substantially higher in patients with pulmonary fibrosis compared with patients without lung involvement. An important study performed a longitudinal evaluation of KL-6 levels in sera of a large cohort of SSc patients. The results demonstrated a marked elevation of KL- 6 levels, which occurred in close temporal association with the clinical diagnosis of pulmonary fibrosis, particularly in patients with positive antitopoisomerase-1 antibodies [75]. Measurements of PS-A and -D were also performed in a cohort of Japanese patients with SSc and it was found that both surfactant-related proteins were significantly elevated in patients with a diagnosis of interstitial lung disease [76]. The same study demonstrated that the sensitivity for the diagnosis and identification of pulmonary fibrosis was higher for the PS-D isoform than for the PS-A isoform. By contrast, the specificity for PS-A was higher than the specificity for PS-D (100\% compared with 83\%). A correlation with functional abnormalities was also established and an important study demonstrated that the levels of PS-D displayed a negative correlation with the vital capacity and diffusion capacity for carbon monoxide [71]. Comparative studies of KL-6 and PS-D demonstrated that there was a positive correlation between the levels of both proteins and there were also similarities in their sensitivity and specificity for the diagnosis of interstitial lung disease [77]. A recent cohort study included in the Scleroderma Lung Study examined the baseline levels of PS-D and KL-6 in patients with or without alveolitis, as defined by high-resolution computerized tomography and bronchioalveolar lavage, and found that overall, SSc patients had higher values for both proteins than normal individuals. Furthermore, significant differences were found in these levels in SSc patients with alveolitis compared to those without [78].

Another potential marker of pulmonary involvement is the pulmonary and activation regulated chemokine (PARC). This chemokine is also known as the (C-C motif) ligand (CCL)-18, and its elevated levels in patients with SSc have been associated with the development of pulmonary fibrosis as well as with reductions in vital capacity and diffusion capacity, and correlated closely with the activity of inflammatory changes in the lungs [79]. Furthermore, PARC levels in bronchioalveolar lavage from SSc patients with active alveolitis correlated with the presence of an inflammatory process in the lungs, as well as with the number and type of inflammatory cells [80].
A recently identified glycoprotein belonging to the chitinase family, YKL-40, has also been suggested as a potential marker for pulmonary involvement in SSc $[81,82]$. Recent studies suggested that levels of YKL-40 may correlate with tissue remodeling and, therefore, may be of value in assessing the pulmonary fibrotic process associated with SSc. Although earlier results were encouraging, elevated levels of the protein have been found in a variety of clinical conditions, including liver fibrosis and numerous malignancies; therefore, the utility of YKL-40 measurements for SSc-associated pulmonary fibrosis needs further evaluation.

\section{Biomarkers of cellular immune system \& cytokine alterations}

The presence of mononuclear cell infiltrates in affected skin and visceral organs from SSc patients has long been recognized. Early in the presentation of SSc, biopsies from affected skin show prominent infiltration with activated macrophages and T- and B-cell lymphocytes [83]. Further expansion of $\mathrm{T}$ cells within the affected tissues appears to be oligoclonal, as demonstrated in studies of T-cell receptor transcripts in SSc skin [84]. The expanded T-cell populations in affected SSc tissues release numerous cytokines, chemokines and growth factors that initiate and/or perpetuate the fibrotic process as well as the endothelial and vascular alterations. Important effects of these released soluble products include the modulation of fibroblast proliferation and the induction of expression of a myofibroblast phenotype with the acquisition of motile cell features, expression of $\alpha$-smooth muscle actin, and a marked increase in their levels of collagen production. These cytokines and growth factors also exert potent effects on vascular wall cells, which results in the development of the typical fibroproliferative/occlusive vasculopathy, including stimulation of proliferation of smooth muscle cells in the media and modification of numerous endothelial cell functions.

Given the crucial role that inflammatory cells and the chronic inflammatory process play in the pathogenesis of various aspects of SSc, extensive efforts have been devoted to identify biomarkers that may reflect the cytokine, chemokine and growth-factor alterations in the disease. The soluble receptor for IL-2 (srIL-2) was one of the earliest identified biomarkers reflecting inflammatory and immunologic activation in SSc. Several studies have demonstrated a close correlation of serum levels of srIL-2 with clinical and disease activity in patients with 
SSc [85-87]. In one of these studies the levels of srIL-2 correlated inversely with the duration of SSc, being more elevated in patients with a recent onset and rapidly progressive forms of the disorder [85]. These values also correlated with the severity and extent of skin sclerosis, as assessed by the mRSS. The serum levels of the soluble receptor for TNF- $\alpha$ (srTNF- $\alpha$ ) have also been proposed as indicators of activity of the immunologic process in SSc, and significant correlations with the severity of SSc and the presence of pulmonary involvement have been described [88,89]. However, subsequent studies have not confirmed whether the serum levels of srTNF- $\alpha$ are useful indicators of the severity or of the rate of progression of the disease, and additional studies are required to further evaluate the validity of srTNF- $\alpha$ serum levels as indicators of the ongoing inflammatory and immune dysfunction in SSc.

A recent study measured the levels of the chemokine CCL-2 in a large cohort of SSc patients and found higher levels in both diffuse and limited cutaneous SSc clinical subsets, although marked CCL-2 elevations were associated with antitopoisomerase or anti-RNA polymerase I/III antibodies, and with a greater frequency of pulmonary and cardiac involvement [90]. Another study examined CCL-2 and chemokine (CXC motif) ligand (CXCL)-10 longitudinally and found that CXCL-10 levels were substantially elevated in newly diagnosed SSc patients and the highest values were associated with more severe clinical manifestations, including pulmonary and kidney involvement [91]. The longitudinal study demonstrated a reduction in CXCL-10 with stable levels of CCL-2, suggesting a temporal switch from a Th1 to a Th2 stage [91]. However, recent studies have demonstrated that levels of these biomarkers are elevated in other disorders, including autoimmune thyroiditis, hepatitis $\mathrm{C}$ infection and psoriatic arthritis. Numerous other cytokines, chemokines and regulatory proteins that are considered to be important participants in the immune activation in SSc have been suggested as potential biomarkers, including CD-40, CCL-2, IL-15, IL-23, BAFF, FAS and others [92-97]. However, further studies to validate their sensitivity and specificity and to confirm their potential usefulness as biomarkers of this process will be required.

\section{Specific biomarkers for fibrosis}

Tissue fibrosis is the hallmark of SSc and is responsible for most of its clinical manifestations. The extent and severity of tissue fibrosis correlates with prognosis and mortality in SSc. However, there is an unmet need for reliable and accurate biomarkers that reflect the fibrotic process in SSc. Since the discovery of the potent profibrotic and immunomodulatory activities of TGF- $\beta$, this pleotropic growth factor has been considered a crucial participant in the pathogenesis of the fibrotic process in SSc and other fibroproliferative diseases [98-100]. One of the most important effects of TGF- $\beta$ is the stimulation of synthesis and production of numerous extracellular matrix molecules involved in tissue fibrosis. TGF- $\beta$ also decreases the synthesis of collagendegrading metalloproteinases and stimulates the production of protease inhibitors, such as tissue inhibitors of metalloproteinase-1. TGF- $\beta$ also induces tissue-resident fibroblasts to change their differentiated phenotype and become myofibroblasts - activated cells capable of producing elevated levels of extracellular matrix macromolecules and expressing $\alpha$-smooth muscle actin. In addition to TGF- $\beta$, numerous studies have demonstrated that CTGF also plays a crucial role in tissue fibrosis owing to its potent profibrotic effects [101]. TGF- $\beta$ stimulates CTGF synthesis in fibroblasts, vascular smooth muscle cells and endothelial cells. CTGF also appears to have an autocrine function stimulating its own production and, thus, maintaining a continuous or prolonged cycle of excessive scarring and fibrosis.

The crucial role of TGF- $\beta$ and CTGF in tissue fibrosis suggests that measurements of their serum levels may reflect the activity of the fibrotic process. However, a recent study measuring TGF- $\beta$ levels in sera from patients with diffuse SSc, in comparison with sera from patients with limited SSc and normal controls, failed to show a correlation with the mRSS, although the values were lower in patients with diffuse SSc than in patients with limited SSc and were even lower than in normal individuals [102]. Few studies have performed measurements of CTGF, although it appears that a circulating peptide containing the $\mathrm{N}$-terminal region of CTGF may be of value as a biomarker of tissue fibrosis [103]. Thus, extensive studies will be required to validate whether measurements of serum levels of these growth factors may be useful biomarkers for the process of fibrosis in the disease.

The increased expression of the genes encoding interstitial collagens types I and III and the marked elevation of the production of the corresponding proteins in SSc led to numerous studies investigating circulating or urinary levels of collagen molecules or collagen fragments as 
biomarkers that may reflect the activity of the ongoing fibrotic process [104-109]. The serum levels of the telopeptide corresponding to the crosslinked carboxy-terminal end of type I collagen, as well as the amino-terminal propeptide of type I procollagen, have been given substantial attention as they reflect the degradation and synthesis of type I collagen, respectively. In one study the levels of the crosslinked carboxy-terminal telopeptide were elevated in more than $80 \%$ of patients with SSc and displayed a positive correlation with the extent of skin involvement [104]. The measurements of the type I procollagen peptide, however, did not discriminate between normal individuals and patients with SSc in this study. A more recent study demonstrated that approximately $50 \%$ of SSc patients had increased serum levels of the carboxy-terminal telopeptide of type I collagen and that these levels correlated with the mRSS and were higher in patients with diffuse cutaneous involvement [105]. Measurements of the amino-terminal type III collagen propeptides appear to be more reflective of the activity of the fibrotic process and substantially elevated levels have been found in patients with SSc compared with controls and patients with diffuse cutaneous SSc and increasing clinical activity $[106,107]$. Elevated levels of type III procollagen peptides also correlated with pulmonary involvement, reduction in vital capacity and diffusion capacity, as well as with the extent of cutaneous involvement [107,108], and were an independent predictor of a poor prognosis and poor surival rate [109]. Although the measurements of metabolites derived from the biosynthesis and degradation of types I and III collagens are likely to be a reflection of the fibrotic process, owing to the fact that most of the type I collagen in the body is present in bone, metabolites derived from this molecule would reflect, to a large extent, the remodeling and degradation of type I collagen in the skeletal system. By contrast, the levels of type III collagen metabolites may be more reflective of a fibrotic process, particularly at the earlier stages of the disease, since it has been generally accepted that type III collagen synthesis is disproportionately increased at the initiation of tissue fibrosis.

Another protein that has been suggested as a potential biomarker to reflect the fibrotic process in SSc is the cartilage oligomeric matrix protein (COMP), which is also an important fibroblast product. Indeed, some studies have measured serum levels of COMP and described significant correlations with the extent of skin involvement and with the severity of SSc [110]. Increased expression of COMP was also demonstrated in skin samples from SSc patients as well as in fibroblasts cultured from these samples [111,112]. However, more extensive studies are required to confirm the validity of COMP as a marker of tissue fibrosis in SSc.

\section{Analysis of gene expression employing microarrays}

The recent development of high-throughput gene-expression profiling technologies, such as cDNA microarrays, combined with advanced computational approaches, have provided basic and clinical investigators with the ability to identify and characterize high-resolution expression profiles of numerous disease states and to dissect molecular networks that underlie specific disease phenotypes. Within a few years following their introduction, microarrays are now routinely used in almost every line of biomedical research, with the most impressive examples of the successful utilization of this technology occuring in cancer research. In the field of SSc research, the application of microarray technology holds the promise that it will allow the identification of molecular signatures specific for SSc, which could provide clues to the elucidation of the pathogenetic mechanisms involved or responsible for the disease. Microarrays may also provide valuable molecular signatures that can be used as biomarkers of utility as diagnostic or prognostic tools and as markers of the effectiveness of disease-modifying therapies. Indeed, recent microarray studies of intact skin, peripheral blood mononuclear cells or cultured dermal fibroblasts disclosed distinct patterns of gene expression capable of distinguishing patients with limited SSc from those with diffuse SSc, and allowed the identification of separate subsets within these two groups that correlate with various clinical parameters and internal organ involvement [113-118]. Microarray studies have also been employed to identify specific patterns of gene expression in SSc-associated pulmonary fibrosis [119] and pulmonary hypertension [120], and have identified a subset of SSc patients who display a TGF- $\beta$ signature in their skin [121]. Thus, global gene-expression studies promise to provide molecular signatures that will be useful as molecular biomarkers for the diagnosis of SSc, identification of its clinical subsets, evaluation of effectiveness of disease-modifying therapies, and stratification of patients who may respond and benefit from specific therapies, as recently shown for imatinib mesylate [121,122]. 


\section{Use of proteomics to identify biomarkers}

The field of proteomics is defined as the study of the entire complement of proteins (proteome) present or produced by a cell or organism employing large-scale separation and identification. Proteomic studies related to human diseases attempt to assess and identify qualitative and quantitative protein differences between healthy and diseased cells and have been employed for the discovery of biomarkers. However, proteomics studies in SSc have been very limited and the few studies available have mainly focused on understanding pathophysiologic events rather than identifying disease biomarkers [123,124].

\section{Future perspective}

The diagnosis of SSc at an early stage prior to the occurrence of obvious cutaneous fibrosis is a challenging task. The assessment and unequivocal assignment of the SSc clinical subset (i.e., diffuse cutaneous versus limited cutaneous) and the evaluation of clinical effectiveness of therapeutic interventions is of great relevance to patient management. The ability to accurately separate SSc patients with rapid progression from those with slow progression and to estimate the prognosis of the disease would also be of remarkable clini$\mathrm{cal}$ and therapeutic value. Although there has been substantial effort devoted to the development and identification of useful biomarkers for SSc, we are still very far from reaching the full potential of biomarker research for SSc. The application of novel genomic, global gene expression and proteomic approaches opens up new and promising opportunities to approach this lofty goal.

\footnotetext{
Financial \& competing interests disclosure

SA Jimenez is supported by NIH Grant RO1 AR019616.

The authors have no other relevant affliations or financial involvement with any organization or entity with a financial interest in or financial conflict with the subject matter or materials discussed in the manuscript apart from those disclosed.

No writing assistance was utilized in the production of this manuscript.
}

\section{Executive summary}

\section{Introduction}

- Despite extensive studies to develop outcome measures for systemic sclerosis (SSc), fully validated biomarkers that allow early diagnosis and assessment of disease activity or that carry a predictive prognostic value are not available.

\section{Autoantibodies as systemic sclerosis diagnostic biomarkers}

- Numerous circulating autoantibodies highly specific for SSc, for example anti-scleroderma-70 and anticentromere antibodies, are used as diagnostic biomarkers to support or confirm the clinical diagnosis of SSC.

\section{Biomarkers for clinical disease subset classification}

- Some autoantibodies are biomarkers of the clinical disease subset, namely anticentromere antibodies for the limited SSc subset, and scleroderma-70, anti-RNA polymerase I and III, and antifibrillarin antibodies for the diffuse form of SSC.

\section{Biomarkers of endothelial cell dysfunction}

- Numerous molecules involved in various aspects of the pathogenesis of endothelial dysfunction (e.g., von Willebrand factor, adhesion molecules and VEGF) are potential biomarkers for endothelial perturbations in SSC.

\section{Biomarkers of pulmonary hypertension}

- Endothelin-1 and N-terminal probrain natriuretic peptide plasma levels are biomarkers for the detection and monitoring of pulmonary artery hypertension and may serve as surrogate markers to evaluate the effects of therapeutic agents for SSc-related pulmonary artery hypertension.

\section{Biomarkers of pulmonary fibrosis}

- Serum levels of Krebs von den Lungen 6 antigen, pulmonary surfactants A and D, and pulmonary and activation regulated chemokine are indicators of the development of pulmonary fibrosis in SSC.

\section{Biomarkers of cellular immune system \& cytokine alterations}

- The levels of numerous cytokines and chemokines that reflect the participation of immune and inflammatory processes have been suggested as potential biomarkers.

\section{Specific biomarkers for fibrosis}

- Circulating or urinary levels of molecules or fragments of interstitial type I and III collagens are potential biomarkers for the activity of the ongoing fibrotic process.

- Elevated levels of type III procollagen peptides correlate with pulmonary involvement and predict a poor prognosis and an unfavorable survival.

\section{Analysis of gene expression employing microarrays \& use of proteomics to identify biomarkers}

- The application of novel genomic, global gene expression and proteomic approaches opens up new and promising opportunities for the development of useful SSC biomarkers and has already allowed the identification of patient subsets with specific signatures that may indicate different pathophysiological events or differential therapeutic responses. 


\section{Bibliography}

1 Gabrielli A, Avvedimento EV, Krieg T: Scleroderma. N. Engl. J. Med. 360, 1989-2003 (2009).

2 Bolster MB, Silver RM: Clinical features of systemic sclerosis. In: Rheumatology. Hochberg MC, Silman AJ, Smolen JS, Weinblatt ME, Weisman MH (Eds). Mosby Elsevier, Philadelphia, PA, USA 1375-1385 (2008).

3 Jimenez SA, Derk CT: Following the molecular pathways toward an understanding of the pathogenesis of systemic sclerosis. Ann. Int. Med. 140, 37-50 (2004).

4 Varga J, Abraham D: Systemic sclerosis: a prototypic multisystem fibrotic disorder. J. Clin. Invest. 117, 557-567 (2007).

5 Medsger TA Jr: Natural history of systemic sclerosis and the assessment of disease activity, severity, functional status, and psychologic well-being. Rheum. Dis. Clin. North Am. 29, 255-273 (2003).

6 Meyer OC, Fertig N, Lucas M, Somogyi N, Medsger TA Jr: Disease subsets, antinuclear antibody profile, and clinical features in 127 French and 247 US adult patients with systemic sclerosis. J. Rheumatol. 34, 104-109 (2007).

7 Perera A, Fertig N, Lucas M et al.: Clinical subsets, skin thickness progression rate, and serum antibody levels in systemic sclerosis patients with antitopoisomerase I antibody. Arthritis Rheum. 56, 2740-2746 (2007).

8 Abraham DJ, Varga J: Scleroderma: from cell and molecular mechanisms to disease models. Trends Immunol. 26, 587-595 (2005).

9 Fleming JN, Schwartz SM: The pathology of scleroderma vascular disease. Rheum. Dis. Clin. North Am. 34, 41-55 (2008).

10 Kahaleh B: Vascular disease in scleroderma: mechanisms of vascular injury. Rheum. Dis. Clin. North Am. 34, 57-71 (2008).

11 Mulligan-Kehoe MJ, Simons M: Vascular disease in scleroderma: angiogenesis and vascular repair. Rheum. Dis. Clin. North Am. 34, 73-79 vi (2008).

12 Merkel PA, Clements PJ, Reveille JD et al: Current status of outcome measure development for clinical trials in systemic sclerosis: report from OMERACT 6. J. Rheumatol. 30, 1630-1647 (2003).

13 Furst DE, Khanna D, Mattucci-Cerinic M et al.: Scleroderma - developing measures of response. J. Rheumatol. 32, 2477-2480 (2005).

14 Gazi H, Pope JE, Clements P et al.: Outcome measurements in scleroderma: results from a delphi exercise. J. Rheumatol. 34, 501-509 (2007).
15 Hudson M, Steele R, Baron M, Canadian Scleroderma Research Group (CSRG): Update on indices of disease activity in systemic sclerosis. Semin. Arthritis Rheum. 37, 93-98 (2007).

16 Khanna D, Merkel PA: Outcome measures in systemic sclerosis: an update on instruments and current research. Curr. Rheumatol. Rep. 9, 151-157 (2007).

17 Feng Q, Yu M, Kiviat NB: Molecular biomarkers for cancer detection in blood and bodily fluids. Crit. Rev. Clin. Lab. Sci. 43, 497-560 (2006).

18 Jain KK: Cancer biomarkers: current issues and future directions. Curr. Opin. Mol. Ther. 9, 563-571 (2007).

19 Vittorini S, Clerico A: Cardiovascular biomarkers: increasing impact of laboratory medicine in cardiology practice. Clin. Chem. Lab. Med. 46, 748-763 (2008).

20 May A, Wang TJ: Biomarkers for cardiovascular disease: challenges and future directions. Trends Mol. Med. 14, 261-267 (2008).

21 McHugh NJ, Distler O, Giacomelli R, Riemekasten G: Non organ based laboratory markers in systemic sclerosis. Clin. Exp. Rheumatol. 21, S32-S38 (2003).

22 Pollard KM, Reimer G, Tan EM: Autoantibodies in scleroderma. Clin. Exp. Rheumatol. 7, x57-x62 (1989).

23 Steen VD: Autoantibodies in systemic sclerosis. Semin. Arthritis Rheum. 35, 35-42 (2005).

24 Ho KT, Reveille JD: The clinical relevance of autoantibodies in scleroderma. Arthritis Res. Ther. 5, 80-93 (2003).

25 Koenig M, Dieudé M, Senécal JL: Predictive value of antinuclear autoantibodies: the lessons of the systemic sclerosis autoantibodies. Autoimmun. Rev. 7, 588-593 (2008).

26 Basu D, Reveille JD: Anti-scl-70. Autoimmunity 38, 65-72 (2005).

27 Czömpöly T, Simon D, Czirják L, Németh P: Antitopoisomerase I autoantibodies in systemic sclerosis. Autoimmun. Rev. 8, 692-696 (2009).

28 Kallenberg CG: Anti-centromere antibodies (ACA). Clin. Rheumatol. 9, S136-S139 (1990).

29 Derk CT, Jimenez SA: Systemic sclerosis: current views of its pathogenesis. Autoimmun. Rev. 2, 181-191 (2003).

30 Meyer O: Prognostic markers for systemic sclerosis. Joint Bone Spine 73, 490-494 (2006).

31 Grassegger A, Pohla-Gubo G, Frauscher M, Hintner H: Autoantibodies in systemic sclerosis (scleroderma): clues for clinical evaluation. Wien. Med. Wochenschr. 158, 19-28 (2008).
32 Ferri C, Bernini L, Cecchetti R et al.: Cutaneous and serologic subsets of systemic sclerosis. J. Rheumatol. 18, 1826-1832 (1991).

33 Jacobsen S, Ullman S, Shen GQ, Wiik A, Halberg P: Influence of clinical features, serum antinuclear antibodies, and lung function on survival of patients with systemic sclerosis. J. Rheumatol. 28, 2454-2459 (2001).

34 Shand L, Lunt M, Nihtyanova S et al.: Relationship between change in skin score and disease outcome in diffuse cutaneous systemic sclerosis. Arthritis Rheum. 56, 2422-2431 (2007).

35 LeRoy EC: Systemic sclerosis. A vascular perspective. Rheum. Dis. Clin. North Am. 22, 695-708 (1996).

36 Kahaleh MB, Osborn I, LeRoy EC: Increased factor VIII/von Willebrand factor antigen and von Willebrand factor activity in scleroderma and in Raynaud's phenomenon. Ann. Intern. Med. 94, 482-484 (1981).

37 Wigley M: Vascular disease in scleroderma. Clin. Rev. Allergy Immunol. 36, 150-175 (2009).

38 Koch AE, Distler O: Vasculopathy and disordered angiogenesis in selected rheumatic diseases: rheumatoid arthritis and systemic sclerosis. Arthritis Res. Ther. 9(Suppl. 2), S3 (2007).

39 Herrick AL, Illingworth K, Blann A, Hay CR, Hollis S, Jayson MI: von Willebrand factor, thrombomodulin and markers of fibrinolysis in primary Raynaud's phenomenon and systemic sclerosis. Ann. Rheum. Dis. 55, 122-127 (1996).

40 Cerinic MM, Valentini G, Sorano GG et al: Blood coagulation, fibrinolysis, and markers of endothelial dysfunction in systemic sclerosis. Semin. Arthritis Rheum. 32, 285-295 (2003).

41 Kuryliszyn-Moskal A, Klimiuk PA, Sierakowski S: Soluble adhesion molecules (sVCAM-1, sE-selectin), vascular endothelial growth factor (VEGF) and endothelin-1 in patients with systemic sclerosis: relationship to organ systemic involvement. Clin. Rheumatol. 24, 111-116 (2005).

42 Davies CA, Jeziorska M, Freemont AJ, Herrick A: The differential expression of VEGF, VEGFR-2, and GLUT-1 proteins in disease subtypes of systemic sclerosis. Hum. Pathol. 37, 190-197 (2006).

43 Hummers K: Microvascular damage in systemic sclerosis: detection and monitoring with biomarkers. Curr. Rheumatol. Rep. 8, 131-137 (2006).

44 Scheja A, Akesson A, Geborek P et al: Von Willebrand factor propeptide as a marker of disease activity in systemic sclerosis (scleroderma). Arthritis Res. 3, 178-182 (2001). 
45 Kumánovics G, Minier T, Radics J, Pálinkás L, Berki T, Czirják L: Comprehensive investigation of novel serum markers of pulmonary fibrosis associated with systemic sclerosis and dermato/ polymyositis. Clin. Exp. Rheumatol. 26, 414-420 (2008).

46 Mannucci PM, Vanoli M, Forza I, Canciani MT, Scorza R: von Willebrand factor cleaving protease (ADAMTS-13) in 123 patients with connective tissue diseases (systemic lupus erythematosus and systemic sclerosis). Haematologica 88, 914-918 (2003).

47 Braun-Moscovici Y, Nahir AM, Balbir-Gurman A: Endothelin and pulmonary arterial hypertension. Semin. Arthritis Rheum. 34, 442-453 (2004).

48 Sticherling M: The role of endothelin in connective tissue disease. Rheumatology (Oxford) 45(Suppl. 3), iii8-10 (2006).

49 Abraham D, Distler O: How does endothelial cell injury start? The role of endothelin in systemic sclerosis. Arthritis Res. Ther. 9, S2 (2007).

50 Yamane K, Kashiwagi H, Suzuki N et al.: Elevated plasma levels of endothelin-1 in systemic sclerosis. Arthritis Rheum. 34, 243-244 (1991).

51 Abraham DJ, Vancheeswaran R, Dashwood MR et al.: Increased levels of endothelin-1 and differential endothelin type $\mathrm{A}$ and $\mathrm{B}$ receptor expression in scleroderma-associated fibrotic lung disease. Am. J. Pathol. 151, 831-841 (1997).

52 Blann ED, Herrick A, Jayson MI: Altered levels of soluble adhesion molecules in rheumatoid arthritis, vasculitis and systemic sclerosis. Br. J. Rheumatol. 34, 814-819 (1995).

53 Gruschwitz MS, Hornstein OP, von Den Driesch P: Correlation of soluble adhesion molecules in the peripheral blood of scleroderma patients with their in situ expression and with disease activity. Arthritis Rheum. 38, 184-189 (1995).

54 Ihn H, Sato S, Fujimoto M, Takehara K, Tamaki K: Increased serum levels of soluble vascular cell adhesion molecule-1 and E-selectin in patients with systemic sclerosis. Br. J. Rheumatol. 37, 1188-1192 (1998).

55 Denton CP, Bickerstaff MC, Shiwen X et al.: Serial circulating adhesion molecule levels reflect disease severity in systemic sclerosis. Br. J. Rheumatol. 34, 1048-1054 (1995).

56 Distler O, Del Rosso A, Giacomelli R et al.: Angiogenic and angiostatic factors in systemic sclerosis: increased levels of vascular endothelial growth factor are a feature of the earliest disease stages and are associated with the absence of fingertip ulcers. Arthritis Res. 4, R11 (2002).
57 Choi JJ, Min DJ, Cho ML et al.: Elevated vascular endothelial growth factor in systemic sclerosis. J. Rheumatol. 30, 1529-1533 (2003).

58 Chitale S, Al-Mowallad AF, Wang Q, Kumar S, Herrick A: High circulating levels of VEGF-C suggest abnormal lymphangiogenesis in systemic sclerosis. Rheumatology (Oxford) 47, 1727-1728 (2008).

59 Viac J, Schmitt D, Claudy A: Plasma vascular endothelial growth factor levels in scleroderma are not correlated with disease activity. Acta Derm. Venereol. 80, 383 (2000).

60 McLaughlin V, Humbert M, Coghlan G, Nash P, Steen V: Pulmonary arterial hypertension: the most devastating vascular complication of systemic sclerosis. Rheumatology 48, iii25-31 (2009).

61 Ramirez A, Varga J: Pulmonary arterial hypertension in systemic sclerosis: clinical manifestations, pathophysiology, evaluation, and management. Treat. Respir. Med. 3, 339-352 (2004).

62 Steen VD, Medsger TA: Changes in causes of death in systemic sclerosis, 1972-2002. Ann. Rheum. Dis. 66, 940-944 (2007).

63 Schmidt J, Launay D, Soudan B et al: Assessment of plasma endothelin level measurement in systemic sclerosis. Rev. Med. Interne 28, 371-376 (2007).

64 Williams MH, Handler CE, Akram R et al: Role of N-terminal brain natriuretic peptide (N-TproBNP) in scleroderma-associated pulmonary arterial hypertension. Eur. Heart J. 27, 1485-1494 (2006).

65 Allanore $\mathrm{Y}$, Borderie D, Avouac J et al.: High $\mathrm{N}$-terminal pro-brain natriuretic peptide levels and low diffusing capacity for carbon monoxide as independent predictors of the occurrence of precapillary pulmonary arterial hypertension in patients with systemic sclerosis. Arthritis Rheum. 58, 284-291 (2008).

66 Dimitroulas T, Giannakoulas G, Karvounis $\mathrm{H}$ et al: $\mathrm{N}$-terminal probrain natriuretic peptide as a biochemical marker in the evaluation of bosentan treatment in systemic-sclerosis-related pulmonary arterial hypertension. Clin. Rheumatol. 27, 655-658 (2008).

67 Simeoni S, Lippi G, Pucetti A et al.: $\mathrm{N}$-terminal pro-BNP in sclerodermic patients on bosentan therapy for PAH. Rheumatol. Int 28, 657-660 (2008).

68 Mathai SC, Bueso M, Hummers K et al.: Disproportionate elevation of NT-proBNP in scleroderma-related pulmonary hypertension. Eur. Respir. J. 35(1), 95-104 (2009).
69 Wells AU, Steen V, Valentini G: Pulmonary complications: one of the most challenging complications of systemic sclerosis. Rheumatology (Oxford) 48, iii40-4 (2009).

70 Prasse A, Müller-Ouernheim J: Non-invasive biomarkers in pulmonary fibrosis. Respirology 14, 788-795 (2009).

71 Kumánovics G, Minier T, Radics J, Pálinkás L, Berki T, Czirják L:

Comprehensive investigation of novel serum markers of pulmonary fibrosis associated with systemic sclerosis and dermato/ polymyositis. Clin. Exp. Rheumatol. 26, 414-420 (2008).

72 Yamane $\mathrm{K}$, Ihn H, Kubo M et al:: Serum levels of KL- 6 as a useful marker for evaluating pulmonary fibrosis in patients with systemic sclerosis. J. Rheumatol. 27, 930-934 (2000).

73 Sato S, Nagaoka T, Hasegawa M, Nishijima C, Takehara K: Elevated serum KL-6 levels in patients with systemic sclerosis: association with the severity of pulmonary fibrosis. Dermatology 200, 196-201 (2000).

74 Veselý R, Vargová V, Ravelli A et al.: Serum level of KL-6 as a marker of interstitial lung disease in patients with juvenile systemic sclerosis. J. Rheumatol. 31, 795-800 (2004).

75 Yanaba K, Hasegawa M, Hamaguchi Y, Fujimoto M, Takehara K, Sato S: Longitudinal analysis of serum KL-6 levels in patients with systemic sclerosis: association with the activity of pulmonary fibrosis. Clin. Exp. Rheumatol. 21, 429-436 (2003).

76 Takahashi $\mathrm{H}$, Kuroki Y, Tanaka H et al.: Serum levels of surfactant proteins A and D are useful biomarkers for interstitial lung disease in patients with progressive systemic sclerosis. Am. J. Respir. Crit. Care Med. 162, 258-263 (2000).

77 Asano Y, Ihn H, Yamane K et al.: Clinical significance of surfactant protein $\mathrm{D}$ as a serum marker for evaluating pulmonary fibrosis in patients with systemic sclerosis. Arthritis Rheum. 44, 1363-1369 (2001).

78 Hant FN, Ludwicka-Bradley A, Wang HJ et al.; Scleroderma Lung Study Research Group: Surfactant protein D and KL-6 as serum biomarkers of interstitial lung disease in patients with scleroderma. J. Rheumatol. 36, 773-780 (2009).

79 Kodera M, Hasegawa M, Komura K, Yanaba K, Takehara K, Sato S: Serum pulmonary and activation-regulated chemokine/CCL18 levels in patients with systemic sclerosis: a sensitive indicator of active pulmonary fibrosis. Arthritis Rheum. 52, 2889-2896 (2005). 
80 Prasse A, Pechkovsky DV, Toews GB et al: CCL18 as an indicator of pulmonary fibrotic activity in idiopathic interstitial pneumonias and systemic sclerosis. Arthritis Rheum. 56, 1685-1693 (2007).

81 La Montagna G, D’Angelo S, Valentini G: Cross-sectional evaluation of YKL-40 serum concentrations in patients with systemic sclerosis. Relationship with clinical and serological aspects of disease. J. Rheumatol. 30, 2147-2151 (2003).

82 Nordenbaek C, Johansen JS, Hallberg P et al.: High serum levels of YKL-40 in patients with systemic sclerosis are associated with pulmonary involvement. Scand. J. Rheumatol. 34, 293-297 (2005).

83 Kraling BM, Maul GG, Jimenez SA: Mononuclear cellular infiltrates in clinically involved skin from patients with systemic sclerosis of recent onset predominantly consists of monocytes/macrophages. Pathobiology 63, 48-56 (1995).

84 Sakkas LI, Xu B, Artlett CM, Lu S, Jimenez SA, Platsoucas CD: Oligoclonal $\mathrm{T}$ cell expansion in the skin of patients with systemic sclerosis. J. Immunol. 168, 3649-3659 (2002).

85 Degiannis D, Seibold JR, Czarnecki M, Raskova J, Raska K Jr: Soluble interleukin-2 receptors in patients with systemic sclerosis. Clinical and laboratory correlations. Arthritis Rheum. 33, 375-380 (1990).

86 Steen VD, Engel EE, Charley MR, Medsger TA Jr: Soluble serum interleukin 2 receptors in patients with systemic sclerosis. J. Rheumatol. 23, 646-649 (1996).

87 Becvár R, Stork J, Pesáková V et al.: Clinical correlations of potential activity markers in systemic sclerosis. Ann. NY Acad. Sci. 1051, 404-412 (2005).

88 Majewski S, Wojas-Pelc A, Malejczyk M, Szymanska E, Jablonska S: Serum levels of soluble TNF $\alpha$ receptor type I and the severity of systemic sclerosis. Acta Derm. Venereol. 79, 207-210 (1999).

89 Gruschwitz MS, Albrecht M, Vieth G, Haustein UF: In situ expression and serum levels of tumor necrosis factor- $\alpha$ receptors in patients with early stages of systemic sclerosis. J. Rheumatol. 24, 1936-1943 (1997).

90 Carulli MT, Handler C, Coghlan JG, Black CM, Denton CP: Can CCL2 serum levels be used in risk stratification or to monitor treatment response in systemic sclerosis? Ann. Rheum. Dis. 67, 105-109 (2008).

91 Antonelli A, Ferri C, Fallahi P et al.: CXCL10 $\alpha$ and CCL $2 \beta$ chemokines in systemic sclerosis - a longitudinal study. Rheumatology (Oxford) 47, 45-49 (2008).
92 Komura K, Fujimoto M, Matsushita T et al: Increased serum soluble CD40 levels in patients with systemic sclerosis. J. Rheumatol. 34, 353-358 (2007).

93 Allanore Y, Borderie D, Meune C et al:: Increased plasma soluble CD 40 ligand concentrations in systemic sclerosis and association with pulmonary arterial hypertension and digital ulcers. Ann. Rheum. Dis. 64, 481-483 (2005).

94 Wuttge DM, Wildt M, Geborek P, Wollheim FA, Scheja A, Akesson A: Serum IL-15 in patients with early systemic sclerosis: a potential novel marker of lung disease. Arthritis Res. Ther. 9, R85 (2007).

95 Komura K, Fujimoto M, Hasegawa M et al.: Increased serum interleukin 23 in patients with systemic sclerosis. J. Rheumatol. 35 , 120-125 (2008).

96 Matsushita T, Hasegawa M, Yamaba K, Kodera M, Takehara K, Sato S: Elevated serum BAFF levels in patients with systemic sclerosis: enhanced BAFF signaling in systemic sclerosis B lymphocytes. Arthritis Rheum. 54, 192-201 (2006).

97 Matsushita T, Fujimoto M, Hasegawa M et al:: Elevated serum APRIL levels in patients with systemic sclerosis: distinct profiles of systemic sclerosis categorized by APRIL and BAFF. J. Rheumatol. 34, 2056-2062 (2007).

98 Prud'homme GJ: Pathobiology of transforming growth factor $\beta$ in cancer, fibrosis and immunologic disease, and therapeutic considerations. Lab. Invest. 87, 1077-1091 (2007).

99 Varga J, Whitfield ML: Transforming growth factor- $\beta$ in systemic sclerosis (scleroderma). Front. Biosci. S1, 226-235 (2009).

100 Varga J, Pasche B: Transforming growth factor $\beta$ as a therapeutic target in systemic sclerosis. Nat. Rev. Rheumatol. 5, 200-206 (2009).

101 Leask A, Holmes A, Abraham DJ: Connective tissue growth factor: a new and important player in the pathogenesis of fibrosis. Curr. Rheumatol. Rep. 4, 136-142 (2002).

102 Dziadzio M, Smith RE, Abraham DJ, Black CM, Denton CP: Circulating levels of active transforming growth factor $\beta 1$ are reduced in diffuse cutaneous systemic sclerosis and correlate with the modified Rodnan skin score. Rheumatology (Oxford) 44, 1518-1524 (2005).

103 Dziadzio M, Usinger W, Leask A et al.: $\mathrm{N}$-terminal connective tissue growth factor is a marker of the fibrotic phenotype in scleroderma. Q. J. Med. 98, 485-492 (2005).
104 Hunzelmann N, Risteli J, Risteli L et al.: Circulating type I collagen degradation products: a new serum marker for clinical severity in patients with scleroderma? Br. J. Dermatol. 139, 1020-1025 (1998).

105 Allanore Y, Borderie D, Lemaréchal H, Cherruau B, Ekindjian OG, Kahan A: Correlation of serum collagen I carboxyterminal telopeptide concentrations with cutaneous and pulmonary involvement in systemic sclerosis. J. Rheumatol. 30, 68-73 (2003).

106 Black CM, McWhirter A, Harrison NK, Kirk JM, Laurent GJ: Serum type III procollagen peptide concentrations in systemic sclerosis and Raynaud's phenomenon: relationship to disease activity and duration. Br. J. Rheumatol. 28, 98-103 (1989).

107 Becvár R, Stork J, Pesáková V et al.: Clinical correlations of potential activity markers in systemic sclerosis. Ann. NY Acad. Sci. 1051, 404-412 (2005).

108 Becvár R, Hulejová H, Braun M, Stork J: Collagen degradation products and proinflammatory cytokines in systemic and localized scleroderma. Folia Biol. (Praha) 53, 66-68 (2007).

109 Nagy Z, Czirják L: Increased levels of amino terminal propeptide of type III procollagen are an unfavorable predictor of survival in systemic sclerosis. Clin. Exp. Rheumatol. 23, 165-172 (2005).

110 Hesselstrand R, Kassner A, Heinegård D, Saxne T: COMP: a candidate molecule in the pathogenesis of systemic sclerosis with a potential as a disease marker. Ann. Rheum. Dis. 67, 1242-1248 (2008).

111 Farina G, Lemaire R, Korn JH, Widom RL: Cartilage oligomeric matrix protein is overexpressed by scleroderma dermal fibroblasts. Matrix Biol. 25, 213-222 (2006).

112 Farina G, Lemaire R, Pancari P, Bayle J, Widom RL, Lafyatis R: Cartilage oligomeric matrix protein expression in systemic sclerosis reveals heterogeneity of dermal fibroblast responses to transforming growth factor $\beta$. Ann. Rheum. Dis. 68, 435-441 (2009).

113 Whitfield ML, Finlay DR, Murray JI et al.: Systemic and cell type-specific gene expression patterns in scleroderma skin. Proc. Natl Acad. Sci. USA 100, 12319-12324 (2003).

114 Tan FK, Hildebrand BA, Lester MS et al.: Classification analysis of the transcriptosome of nonlesional cultured dermal fibroblasts from systemic sclerosis patients with early disease. Arthritis Rheum. 52, 865-876 (2005). 
115 Gardner H, Shearstone JR, Bandaru R et al.: Gene profiling of scleroderma skin reveals robust signatures of disease that are imperfectly reflected in the transcript profiles of explanted fibroblasts. Arthritis Rheum. 54, 1961-1973 (2006).

116 Pendergrass SA, Whitfield ML, Gardner H: Understanding systemic sclerosis through gene expression profiling. Curr. Opin. Rheumatol. 19, 561-567 (2007).

117 Milano A, Pendergrass SA, Sargent JL et al: Molecular subsets in the gene expression signatures of scleroderma skin. PLoS ONE 3, e2696 (2008).

118 Bos CL, van Baarsen LG, Timmer TC et al.: Molecular subtypes of systemic sclerosis in association with anticentromere antibodies and digital ulcers. Genes Immun. 10, 210-218 (2009).
119 Renzoni EA, Abraham DJ, Howat $S$ et al.: Gene expression profiling reveals novel TGF $\beta$ targets in adult lung fibroblasts. Respir. Res. 5, 24 (2004).

120 Grigoryev DN, Mathai SC, Fisher MR et al.: Identification of candidate genes in scleroderma-related pulmonary arterial hypertension. Transl. Res. 151, 197-207 (2008).

121 Sargent JL, Milano A, Bhattacharyya S et al:: A TGF $\beta$-responsive gene signature is associated with a subset of diffuse scleroderma with increased disease severity. J. Invest. Dermatol. doi: 10.1038/ jid.2009.318 (2009) (Epub ahead of print).

122 Chung L, Fiorentino DF, Benbarak MJ et al:: Molecular framework for response to imatinib mesylate in systemic sclerosis. Arthritis Rheum. 60, 584-591 (2009).
123 Aden N, Shiwen X, Aden D et al.: Proteomic analysis of scleroderma lesional skin reveals activated wound healing phenotype of epidermal cell layer. Rheumatology 47, 1754-1760 (2008).

124 Bogatkevish GS, Ludwicka-Bradley A, Singleton CB, Bethard JR, Silver RM: Proteomic analysis of CTGF-activated lung fibroblasts: identification of IQGAP1 as a key player in lung fibroblast migration. Am. J. Physiol. Lung Cell Mol. Physiol. 295, L603-L611 (2008). 